\title{
Indigenous Nursing Students' Readiness for Practice Perceptions - Les perceptions d'étudiantes autochtones en sciences infırmières quant à leur préparation à la pratique
}

\author{
Noelle Rohatinsky \\ University of Saskatchewan, noelle.rohatinsky@usask.ca \\ Heather Exner-Pirot \\ University of Saskatchewan, heather.exnerpirot@usask.ca \\ Michèle Parent-Bergeron \\ Laurentian University, michele.parent@alumni.utoronto.ca \\ Kristopher Bosevski \\ University of Saskatchewan, krb742@mail.usask.ca \\ Carrie Pratt \\ University of Saskatchewan, carrieann.pratt@gmail.com
}

Follow this and additional works at: https://qane-afi.casn.ca/journal

Part of the Nursing Commons

\section{Recommended Citation}

Rohatinsky, Noelle; Exner-Pirot, Heather; Parent-Bergeron, Michèle; Bosevski, Kristopher; and Pratt, Carrie (2018) "Indigenous Nursing Students' Readiness for Practice Perceptions - Les perceptions d'étudiantes autochtones en sciences infirmières quant à leur préparation à la pratique," Quality Advancement in Nursing Education - Avancées en formation infirmière: Vol. 4: Iss. 2, Article 3.

DOI: https://doi.org/10.17483/2368-6669.1133

This Article is brought to you for free and open access by Quality Advancement in Nursing Education - Avancées en formation infirmière. It has been accepted for inclusion in Quality Advancement in Nursing Education - Avancées en formation infirmière by an authorized editor of Quality Advancement in Nursing Education - Avancées en formation infirmière. 


\section{Indigenous Nursing Students' Readiness for Practice Perceptions - Les perceptions d'étudiantes autochtones en sciences infirmières quant à leur préparation à la pratique}

\section{Cover Page Footnote}

The researchers would like to acknowledge funding from Community Engagement and Outreach at the University of Saskatchewan and Sigma Theta Tau International, Xi Lambda Chapter. The researchers thank the Social Sciences and Research Laboratories for assistance with data analysis. The researchers would also like to acknowledge the contributions of the nursing student participants within this study. Les chercheurs ont reçu du financement de Community Engagement and Outreach (Implication communautaire) de la University of Saskatchewan et de Sigma Theta Tau International (chapitre Xi Lambda). Ils aimeraient aussi remercier les laboratoires des sciences sociales et de la recherche pour leur aide dans l'analyse de données. Les chercheurs désirent également souligner la contribution des étudiantes en sciences infirmières qui ont participé à cette étude. 


\section{Introduction}

The literature has long explored transition to practice struggles for new graduate nurses. However, no studies of which we are aware have addressed Indigenous senior nursing students' perspectives on this topic. The purpose of this research is to explore baccalaureate Indigenous nursing students' perceptions of their readiness for practice.

\section{Background}

Within Canada, except in Québec, a baccalaureate degree is a requirement for entry to practice in nursing (Canadian Association of Schools of Nursing [CASN], 2016). Baccalaureate nursing programs prepare graduates to be generalist practitioners by providing foundational knowledge in nursing science, growth and development, health related needs of diverse populations, organizational structures, information technology, and relational practice with individuals, families, and communities across the lifespan (CASN, 2015). Graduates of baccalaureate programs are able to develop critical thinking, clinical reasoning, self-evaluation, self-regulation, and inter-professional practice skills (CASN, 2016).

While Canadian nurse educators are confident that new graduates have been given the requisite knowledge, skills, and abilities to be competent in practice, senior students and new graduates often lack confidence in their abilities and frequently feel overwhelmed with respect to their upcoming registered nurse role (Guner, 2014; Hickey, 2010; Saber, Anglade, \& Schirle, 2015). New graduates expect some level of discomfort when transitioning from student to nurse, lack confidence in their abilities, and are apprehensive at the thought of assuming total responsibility for patient care (Andrews, 2013; Guner, 2014; Kumaran \& Carney, 2014; Saber et al., 2015). Specifically, nursing students commonly feel unprepared in their upcoming roles in the areas of decision-making, leadership, and time management (Guner, 2014; Saber et al., 2015). Students and new graduates wish for additional clinical time in their undergraduate programs to allow them to practice skills such as prioritization, health care professional interactions, and caring for multiple patients (Guner, 2014; Hickey, 2010; Saber et al., 2015). Students also identify the "theory-practice gap" when comparing their undergraduate education with the realities of the nursing profession (Guner, 2014; Kumaran \& Carney, 2014).

As nursing graduates enter the workforce, they are faced with numerous challenges and expectations surrounding their new career path (Duclos-Miller, 2011) and experience a period of "transition shock" within their new role (Boychuk Duchscher, 2009). Transitioning from student to practitioner brings with it exceedingly stressful and overwhelming experiences. These challenges are only exacerbated when new graduates self-identify as Indigenous, as they often face unique transitional challenges, such as a lack of emotional and moral support, racism, and discrimination within the workplace (Loftin, Newman, Dumas, Gilden, \& Bond, 2012; Vakic, Jesty, Mathews, \& Etowa, 2012). These experiences ultimately add to the stress new graduates endure during the transition process and can contribute to lack of confidence in the workplace, which inevitably creates doubt about their capabilities of being a nurse and performing the necessary day-to-day tasks (Dyess \& Sherman, 2009).

\section{Indigenous Peoples' Health}

The term Indigenous is an international name given to the original peoples of North America and their descendants. "The Canadian Constitution recognizes three distinct groups of Indigenous (Aboriginal) peoples: Indians (referred to as First Nations), Métis and Inuit" 
(Government of Canada, 2017, para. 1). The Province of Saskatchewan has one of the highest proportions of First Nations and Métis residents in Canada, at 16\% in 2011, and this number is expected to increase to approximately $20 \%$ of the provincial population by 2036 (Statistics Canada, 2015). An understanding of physical, mental, emotional, spiritual, and historical aspects is crucial to the provision of quality care and health outcomes of Indigenous people (Kulig et al., 2010; Reading \& Wien, 2013; Truth and Reconciliation Commission of Canada [TRC], 2015). Indigenous patient experiences related to structural violence have shaped the health of Indigenous peoples and communities globally and are deeply embedded in history, discrimination, individual and institutional racism, and inequitable social policies and practices (Browne, 2017; Browne et al., 2016).

The health of Indigenous peoples throughout the world is shaped by common global colonial and neocolonial forces (Browne, 2017; Browne et al., 2016). Colonialism, racism, social exclusion, and the Indian Act are some of the root causes of persistent health inequities and poor health status for Indigenous peoples across Canada (Allan \& Smylie, 2015; Reading \& Wien, 2013). Cultural safety contributes to the achievement of positive health outcomes and experiences of Indigenous peoples whereas unsafe cultural practice comprises any action that diminishes, demeans, or disempowers the cultural identity and well-being of Indigenous peoples (Nursing Council of New Zealand, 2011). Cultural safety is considered an essential component when caring for Indigenous clients and communities (Aboriginal Nurses Association of Canada [A.N.A.C.], 2009).

Indigenous registered nurses (RNs) are considered experts in providing care to Indigenous peoples due to their own lived experiences (Exner-Pirot \& Butler, 2015). Research suggests that cultural congruency between health care providers and clients results in effective client-provider relationships and enhanced satisfaction with care provided, which can influence the future health status of Indigenous populations and help to reduce the systemic discrimination and racism within the health care system (Banister, Bowen-Brady, \& Winfrey, 2014; Minore et al., 2013). As such, culturally safe care requires not only appropriate efforts from non-Indigenous nurses but a full representation of Indigenous nurses in the Canadian health care system. In Canada, 2.9\% of registered nurses (>7900 individuals) are Indigenous, and Saskatchewan has one of the highest provincial levels $(6.1 \%)$ in the country (Exner-Pirot, 2014; Gregory \& Barsky, 2007; Hoffart, Waddell, \& Young, 2011). Despite these rates and the understanding that the availability of Indigenous RNs has been linked to improved health status of Indigenous individuals and communities, various issues still hinder the success of new Indigenous nursing graduates (Canadian Nurses Association \& Aboriginal Nurses Association of Canada, 2014; Kulig et al., 2010; Smith, McAlister, Tedford Gold, \& Sullivan-Bentz, 2011; Vukic et al., 2012). Racial challenges, strained interprofessional relationships, and lack of inclusivity in the workplace can affect the already stressful environment for a new nurse, thus influencing job satisfaction, retention, and the risk of nurse turnover (Carr, Palepu, Szalacha, Caswell, \& Inui, 2007; Kulig et al., 2010; Vakic et al., 2012).

\section{Indigenous Nursing Student Educational Experiences}

High attrition rates are noted among Indigenous nursing students (Gregory \& Barsky, 2007; West, Usher, Buettner, Forster, \& Stewart, 2013). Researchers have examined various influential factors towards Indigenous nursing students' retention and successful completion of their nursing program and include personal and institutional factors. 
Personal factors. Many personal factors influence student retention and success in nursing education programs. Personal motivation for enrolling in an undergraduate nursing program, dedication and commitment to their studies, and the desire to make a difference in the health outcomes of Indigenous clients and communities positively influence the students' success (Harder, Astle, Grypma, \& Voyageur, 2016; West et al., 2013). Confidence in their Indigenous identity and self-efficacy allow for students to be successful in their programs (West et al., 2013).

Family responsibilities and community considerations are deemed to be significant influences on student success (Anonson, Desjarlais, Nixon, Whiteman, \& Bird, 2008; FeltonBusch, Solomon, McBain, \& De La Rue, 2009; Smith et al., 2011). Indigenous students prefer to reside in communities near their families and support systems while attending university as it provides a ready support system (Harder et al., 2016; Wilson, McKinney, \& Rapata-Hanning, 2011). Relocating to areas away from family can result in attrition (Smith et al., 2011). Availability of childcare when students are in school also influences student success (Anonson et al., 2008; Felton-Busch et al., 2009). Communities can be perceived as positive and negative influences on nursing student success. For example, community members are proud and supportive of Indigenous students for obtaining a university education. However, some members may also feel that the nursing student is "too good" for the members of the community (Anonson et al., 2008). Family and community can place high demands on the student, and these demands can negatively influence their program completion (Anonson et al., 2008; West et al., 2013).

Institutional factors. Several institutional factors are seen as supportive for Indigenous nursing student success and frequently include monetary, academic and non-academic, and social supports (Metz, Cech, Babcock, \& Smith, 2011). Financial support in the form of loans, scholarships, and bursaries are considered facilitative factors in program retention and completion (Anonson, et al., 2008; Cech, Metz, Babcock, \& Smith, 2011; Ferrell, DeCrane, Edwards, Foli, \& Tennant, 2016; Harder et al., 2016; Parent, 2010; Pijl \& Hagen, 2011). However, Cech et al. (2011) identify that financial supports are perceived as less important by Indigenous students than other institutional supportive factors.

Informational supports include others providing guidance and direction with academic and non-academic related issues and can be provided by academic advisors (Cech et al., 2011; Pijl \& Hagen, 2011). Academic-related informational support includes facilitation of student study groups or access to tutors (Cech et al., 2011; Ferrell et al., 2016; Parent, 2010). While many students have access to tutoring services, only small numbers of students take advantage of these opportunities (Ferrell et al., 2016). Non-academic-related information supports include assistance with applying to funding sources and searching for childcare or housing options (Cech et al., 2011; Pijl \& Hagen, 2011).

Social support that includes opportunities for connection with others serves as an important aspect to successful program completion. Being connected with other Indigenous individuals can minimize feelings of cultural isolation and mitigate experiences of racism (Parent, 2010; West et al., 2013). Elders and other Indigenous advisors are seen as influential to support student wellbeing (Cech et al., 2011; Parent, 2010; Pijl \& Hagen, 2011). Indigenous faculty and registered nurses serve as role models and mentors to nursing students and can facilitate their success within the program (Anonson et al., 2008; Cech et al., 2011; Ferrell et al., 2016; Parent, 2010; West et al., 2013). Indigenous peer support also contributes to student success and retention (Cech et al., 2011; Parent, 2010; West et al., 2013). Participation in cultural and family events offered by the 
local community or university is seen as a facilitating factor (Parent, 2010; Pijl \& Hagen, 2011; West et al., 2013).

\section{Indigenous Nursing Student Preparedness}

Promoting a successful transition for Indigenous nursing students into the health care workforce has two direct and significant benefits. The first is that it supports retention of Indigenous nurses in the health care system (Banister et al., 2014). Recruitment and retention of Indigenous nurses within health care systems has been identified as a priority (Canadian Nurses Association \& Aboriginal Nurses Association of Canada, 2014). Retention has consequent benefits as Indigenous nurses are likely more effective at delivering culturally safe care to Indigenous clients. This can improve continuity of care, and thus effectiveness. Indigenous nurses can act as role models, inspiring others of Indigenous heritage to pursue a university education or a nursing career, and they can help reduce economic leakage, being more likely to live in or work with Indigenous communities (Aboriginal Nurses Association of Canada [A.N.A.C.], 2009; Anonson et al., 2008; Exner-Pirot \& Butler, 2015; Katz, O’Neal, Strickland, \& Doutrich, 2010; National Aboriginal Health Organization, 2006). Indigenous registered nurses are able to align their cultural expertise with their clinical expertise in order to provide increased access to culturally safe quality health services (Smith et al., 2011; West et al., 2013). Furthermore, Indigenous nurses can act as role models to non-Indigenous nurses by enacting culturally safe care (West et al., 2013).

The second direct impact is the reduction in costs associated with high turnover and vacancies. Turnover costs per registered nurse, in Canada and the United States, have been estimated at \$25000 to \$88 000 (Jones, 2008; O’Brien-Pallas, Tomblin-Murphy, \& Shamian, 2008). Remote Indigenous communities often offer hiring and retention bonuses in the thousands of dollars (Nunavut Nurses, 2014); some have faced retention rates as low as $10 \%$ (attrition of 45/50 nurses) over a three-year period (Porter, 2012). Redirecting the burden associated with turnover, not only the financial costs associated with hiring and retention costs, training, and overtime, but also nursing staff burnout and fatigue, to improve primary health care services in Indigenous communities would be helpful in improving health indicators and outcomes.

By understanding the readiness for practice perceptions of Indigenous nursing students and facilitating the successful transition from student to nurse, nursing education programs can honour the TRC's (2015) Calls to Action related to 1) increasing the number of Indigenous professionals working in the health care field and 2) ensuring the retention of Indigenous health care providers in Indigenous communities. Overall, Indigenous people represent an important and growing part of the Saskatchewan and Canadian populations, and this study aims to address the lack of literature regarding Indigenous nursing students' preparedness for practice.

\section{Research Question}

What is the readiness for practice perceptions of senior undergraduate nursing students of Indigenous ancestry?

\section{Methods}

\section{Research Design and Survey Instrument}

A descriptive, exploratory study design is utilized for this project. Senior students completed the Readiness for Practice Survey, which was developed by two registered nurses in the United States (Casey et al., 2011), in a 10-minute online or paper format. Although this survey was created in the United States, it is non-specific and universally applicable to the Canadian senior 
nursing student context. The survey is used to measure senior nursing students' perceived readiness for practice in several areas and is divided into three sections: 1) demographic data, 2) a self-report on level of confidence and comfortability with both clinical and relational skills, and 3) an open-ended question related to students' perceptions on what could have assisted them to feel more prepared to enter nursing practice. The demographic data section contains questions on age, gender, ethnicity, and the students' acute care final clinical practicum. Questions added to this section are specific to the local university context, including the physical location of nursing program and nursing employment preferences, such as full-time or part-time status, health region of choice, and a preference for an urban and rural work site. The second section on confidence and comfortability is divided into several parts. Participants are first asked to select the top three skills they are most uncomfortable performing independently from a list of 20 procedures and skills. Students are then asked to rate their level of confidence in caring for two, three, and four patients. Finally, students are presented with a 20-item Likert scale divided into four domains of readiness subscales: clinical problem solving (7 items, Cronbach's alpha .80), learning techniques ( 2 items, Cronbach's alpha .50), professional identity (5 items, Cronbach's alpha .65), and trials and tribulations (6 items, Cronbach's alpha .63) (Casey et al., 2011). This Likert scale is used to highlight domains of readiness and the development of confidence in senior students. A four-point Likert scale is used (strongly disagree, disagree, agree, and strongly agree) with higher scores reflecting greater levels of agreement. The final section of the survey is an open-ended question: What could be done to help you feel more prepared to enter the nursing profession? This survey has undergone psychometric analysis by the survey developers and consists of content and construct validity and exploratory and confirmatory factor analysis (Casey et al., 2011).

\section{Setting and Sample}

The setting for this study is a Western Canadian province. A total of 40 Indigenous senior nursing students within the baccalaureate nursing program at one university were approached as a convenience sample. Ethical approval was obtained prior to study commencement by the University Research Ethics Board (BEH\#15-118). Nursing students were eligible to participate if they voluntarily self-declared Indigenous heritage and would be graduating within the next two months. Participation in the survey was voluntary and participation or lack thereof did not affect student grades, progress in the undergraduate program, or future employment.

The university's College of Nursing has established six sites across the province where students can complete all four years of their program. The College of Nursing's Learn Where You Live philosophy, a driving force behind the establishment of distributed learning sites across the province, has been instrumental to Indigenous student recruitment and retention (Exner-Pirot \& Butler, 2015). Geographic access to education and proximity to Indigenous communities have been significant factors in the College's recruitment success.

In 1984, the College of Nursing established the National Native Access Program to Nursing (NNAPN) to provide personal supports and improve the transition and success of First Nations and Métis students into nursing programs; this initiative is the first of its kind in Canada. The College continues to be at the forefront of efforts to recruit and retain Indigenous students, both within the university and with respect to nursing programs across the country. The College reserves $16.6 \%$ (57) of the seats each year for Indigenous applicants; in the 2016-2017 academic year, 191 Indigenous undergraduate students were enrolled across the four years of the program (representing $18.9 \%$ of the total student body). Nationwide data on Indigenous nursing student proportions has not been collected since 2007, at which time this particular Western Canadian 
province had the highest Indigenous student numbers (211) in the country (Gregory \& Barsky, 2007). The retention rate of Indigenous students in the College of Nursing is $93 \%$ (versus $95 \%$ for the total nursing student population, and versus $63 \%$ for the university's total Indigenous student population).

\section{Participant Recruitment}

Several recruitment initiatives were utilized: potential participants were sent a letter of invitation via email by a non-researcher assistant to participate in the research project, the research project was described via video recording and posted online for students, and an in-person description with the opportunity to ask questions was provided. Students were offered $\$ 10$ cash as an incentive to participate. Due to accounting requirements implemented by the university research system, a demographic form, separate from the anonymous survey, was completed by each student who participated in the study in order to receive the $\$ 10$ honorarium. Information gathered by a non-researcher assistant included student name and mailing and email address and this information could not be linked with individual survey completion.

\section{Data Collection and Analysis}

Participants were able to complete the survey either electronically or using a paper copy. An arms-length non-researcher assisted with electronic survey distribution via email and paper survey distribution in person to prevent the perception of coercion of survey completion. Furthermore, the primary investigator, a faculty member, was not currently teaching the students during the time the research project occurred. Researchers were not present in the room when students were given time to complete or decline completing the paper questionnaire, and researchers had no way of knowing who completed the survey and who did not. Survey completion was taken as implied consent. Two participants completed the survey electronically and the remainder completed a paper copy. Quantitative data from the Readiness for Practice Survey were entered, stored, and analyzed using SPSS (v. 23) software. Statistical analysis was conducted by a statistician and included descriptive statistics on demographic data, reliability testing on the corresponding scales, and independent t-tests to make comparisons among groups.

\section{Results}

Twenty-six participants (Table 1) completed the Readiness for Practice Survey. The mean age of participants in years was 29 and the majority were female. Those who voluntarily identified as First Nations or Métis were almost equally represented. The smallest participant numbers were from the northern campus locations. The majority of participants' acute care final practicum placements occurred in an urban setting. 
Table 1.

Demographic Table

\begin{tabular}{ll}
\hline Demographic Characteristics & Number of Participants \\
\hline Age $\quad$ Mean Age (Years) & $29.3 \pm 7.6$ \\
Age Range (Years) & $21-47$ \\
$\quad$ Median Age (Years) & 28 \\
Gender & 2 \\
$\quad$ Male & 24 \\
$\quad$ Female & \\
Ethnicity & 12 \\
$\quad$ First Nations & 14 \\
$\quad$ Métis & 0 \\
$\quad$ Inuit & 17 \\
Acute Care Final Practicum Location & 9 \\
$\quad$ Urban & \\
Rural &
\end{tabular}

\section{Clinical Problem Solving}

The Clinical Problem Solving subscale had a Cronbach's alpha of 0.76, which is comparable to the literature (Casey et al., 2011). The mean for the study sample was derived from the scores of seven questions on the Readiness for Practice Survey. Altogether, the subscale mean was $1.98( \pm 0.35)$. The highest scores were observed for the statements "I use current evidence to make clinical decisions" (mean=2.23), "I am confident in my ability to problem solve" (mean=2.12), and "I feel confident identifying actual or potential safety risks to my patients" (mean=2.12). The lowest mean score was observed for the statement "I feel comfortable knowing what to do for a dying patient" (mean=1.58). Independent t-tests were used to determine any significant differences in scores across those who completed their final acute care practicum in urban versus rural settings. Those who worked in rural settings had a higher mean score on this subscale, but the difference from urban settings was not significant $(2.10( \pm 0.35)$ vs. $1.92( \pm 0.35)$; $\mathrm{p}=.22$ ).

\section{Learning Techniques}

The Learning Techniques subscale had a Cronbach's alpha of 0.69, which is higher than the 0.50 cited in the literature (Casey et al., 2011). The mean for the study sample $(1.88 \pm 0.68)$ was derived from the scores of only two questions on the Readiness for Practice Survey. Participants had a higher mean score for the statement "Simulations have helped me feel prepared for clinical practice" (mean=2.12), with $88.5 \%$ of students agreeing or strongly agreeing. Although the same number of participants agreed with the statement "Writing reflective journals/logs provided insights into my own clinical decision-making skills", fewer participants strongly agreed (mean=1.85). Students who completed their final acute care practicum in a rural setting also had 
higher mean scores than those from urban settings, but again this difference was not significant $(1.94( \pm 0.77)$ vs. $1.85( \pm 0.66) ; \mathrm{p}=.75)$.

\section{Professional Identity}

The Professional Identity subscale consisted of the mean scores from five statements. Cronbach's alpha for this subscale was low (0.44), and therefore it might not have measured what was intended. Therefore, the results here reflect the means of individual statements rather than the overall subscale mean. The highest mean score was observed for the statement "I am satisfied with choosing nursing as a career" (mean=2.77). Despite this satisfaction, the lowest mean score was observed for the statement "I feel ready for the profession of nursing" (mean=1.88). Overall, the participants agreed they were comfortable asking for help (mean=2.54) and communicating with patients and their families (mean=2.27). There was moderate agreement with the statement "My clinical instructor provided feedback about my readiness to assume the RN role" (mean=2.04). Mean scores from students who completed their final acute care practicum in rural settings were higher than those in urban settings, but again this difference was not significant $(2.42( \pm 0.23)$ vs. $2.24( \pm 0.35) ; \mathrm{p}=.16)$.

\section{Trials and Tribulations}

Much like the subscale for Professional Identity, this subscale had a low Cronbach's alpha (0.42). This subscale included six statements, with the scores for four reverse coded so that higher means reflect higher levels of agreement. Generally, participants disagreed with the statement "I feel overwhelmed by ethical issues in my patient care responsibilities" (mean=0.96). The highest levels of agreement were found for the statement "I have had opportunities to practice skills and procedures more than once" (mean=2.15) and "I am comfortable delegating tasks to the nursing assistant" (mean=1.88). Low levels of agreement were also observed for "I have difficulty prioritizing patient needs" (mean=1.04) and "I have difficulty recognizing change in my patient's condition" (mean=1.15).

\section{Skills that Students Felt Uncomfortable Performing}

From the list of 20 skills and procedures provided (Table 2), most participants indicated they were most uncomfortable performing EKG/telemetry monitoring and interpretation (50\%), responding to an emergency/code blue/changing patient condition (50\%), performing tracheostomy care/suctioning (50\%), performing chest tube care (31\%), drawing blood/venipuncture (19\%), and central line care (19\%). All students indicated they were comfortable performing the following skills independently: assessment skills, blood glucose monitoring, cultural competency, operating IV pumps, and pulse oximetry.

Among students who completed their final acute care practicum in an urban setting, $65 \%$ indicated responding to an emergency/code blue/changing patient condition and tracheostomy care/suctioning were one of the top three skills/procedures about which they felt most uncomfortable. This percentage was substantially lower (22\%) for students who completed their final acute care practicum in a rural setting. No participants who conducted their practicum in an urban setting selected blood draw/venipuncture in their top three, but this was indicated by $56 \%$ of those who conducted their practicum in a rural setting. The one skill both groups seemed uncomfortable with was EKG/telemetry monitoring and interpretation, with this skill selected in their top three by $47 \%$ of urban final practicum students and $56 \%$ of rural final practicum students. 
Table 2.

List of Skills Students Felt Uncomfortable Performing Independently

\begin{tabular}{|c|c|c|c|}
\hline \multirow[t]{2}{*}{ Skill } & \multicolumn{3}{|c|}{ \# of Mentions (\%) } \\
\hline & $\begin{array}{l}\text { Urban } \\
\text { Practicum } \\
(\mathbf{n}=17)\end{array}$ & $\begin{array}{l}\text { Rural } \\
\text { Practicum } \\
(n=9)\end{array}$ & Total \\
\hline Assessment skills & $0(0 \%)$ & $0(0 \%)$ & $0(0 \%)$ \\
\hline Bladder catheter insertion/ irrigation & $0(0 \%)$ & $2(22 \%)$ & $2(8 \%)$ \\
\hline Blood draw/ venipuncture & $0(0 \%)$ & $5(56 \%)$ & $5(19 \%)$ \\
\hline Blood glucose monitoring device & $0(0 \%)$ & $0(0 \%)$ & $0(0 \%)$ \\
\hline $\begin{array}{l}\text { Central line care (dressing change, blood } \\
\text { draws, discontinuing) }\end{array}$ & $2(12 \%)$ & $3(33 \%)$ & $5(19 \%)$ \\
\hline Charting/ documentation & $1(6 \%)$ & $0(0 \%)$ & $1(4 \%)$ \\
\hline Chest tube care & $6(35 \%)$ & $2(22 \%)$ & $8(31 \%)$ \\
\hline Communication & $1(6 \%)$ & $0(0 \%)$ & $1(4 \%)$ \\
\hline Cultural competency & $0(0 \%)$ & $0(0 \%)$ & $0(0 \%)$ \\
\hline $\begin{array}{l}\text { EKG/telemetry monitoring and } \\
\text { interpretation }\end{array}$ & $8(47 \%)$ & $5(56 \%)$ & $13(50 \%)$ \\
\hline Giving verbal report & $0(0 \%)$ & $1(11 \%)$ & $1(4 \%)$ \\
\hline Intravenous (IV) medication administration & $0(0 \%)$ & $1(11 \%)$ & $1(4 \%)$ \\
\hline Intravenous (IV) starts & $1(6 \%)$ & $0(0 \%)$ & $1(4 \%)$ \\
\hline IV pumps/ PCA pump operation & $0(0 \%)$ & $0(0 \%)$ & $0(0 \%)$ \\
\hline Medication administration & $2(12 \%)$ & $0(0 \%)$ & $2(8 \%)$ \\
\hline NG tube/Dobhoff care & $3(18 \%)$ & $2(22 \%)$ & $5(19 \%)$ \\
\hline Pulse oximetry & $0(0 \%)$ & $0(0 \%)$ & $0(0 \%)$ \\
\hline $\begin{array}{l}\text { Responding to an emergency/code blue/ } \\
\text { changing patient condition }\end{array}$ & $11(65 \%)$ & $2(22 \%)$ & $13(50 \%)$ \\
\hline Tracheostomy care/suctioning & $11(65 \%)$ & $2(22 \%)$ & $13(50 \%)$ \\
\hline Wound care/dressing change/wound vac & $0(0 \%)$ & $1(11 \%)$ & $1(4 \%)$ \\
\hline
\end{tabular}

\section{Confidence in Caring for Number of Patients}

Participants indicated their level of comfort in caring for two, three, or four patients using a 5-point Likert scale, with higher scores representing higher levels of confidence. Students became less confident as the number of patients increased. Students who studied at the large urban campus (city population 246,376 (Government of Saskatchewan, 2017) with three tertiary care hospitals) had significantly higher levels of comfort in caring for more patients than those studying nursing at the smaller urban campus (city population of 35,926 (Government of Saskatchewan, 2017) with one tertiary care hospital). Mean scores did not differ between urban and rural campus students for two patients, but did for three patients (3.78 vs. 3.18; $\mathrm{p}=.05)$ and four patients $(3.20$ vs. 2.36; $\mathrm{p}=.04)$. No significant differences were observed between those students doing their final practicum in urban or rural settings. 


\section{Open-ended question}

Responses to the open-ended question (i.e., What could have been done to help you feel more prepared to enter the nursing profession?) were written by students in point form with no additional explanation or rationale for their choices. Many participants gave more than one response. The most frequent suggestions included additional anatomy, physiology, pharmacology, and medical surgical theory courses particularly in upper years of the program, increased clinical hours, opportunities to practice psychomotor skills, and opportunities for mentorship both within school and after graduation. See Table 3 for more information.

Table 3.

List of Strategies Students Identified Would Help Them Feel More Prepared to Enter the Nursing Profession

\begin{tabular}{ll}
\hline Suggested Strategy & $\begin{array}{l}\text { \# of Mentions } \\
(\mathbf{\%})(\mathbf{n}=\mathbf{2 6})\end{array}$ \\
\hline $\begin{array}{l}\text { Additional anatomy, physiology, pharmacology, and medical surgical theory } \\
\text { classes especially in upper years }\end{array}$ & $6(23 \%)$ \\
Additional clinical time and diversity in clinical experiences & $6(23 \%)$ \\
Greater opportunity to practice psychomotor skills & $6(23 \%)$ \\
Mentorship programs during undergraduate education and post-graduation & $6(23 \%)$ \\
Assistance with NCLEX preparation & $5(19 \%)$ \\
Additional interprofessional communication and practice experiences & $3(12 \%)$ \\
Directions for applying for a graduate license & $2(8 \%)$ \\
Greater exposure to paperwork and computer work related to nursing. & $2(8 \%)$ \\
Greater information about process of transitioning from student to graduate & $2(8 \%)$ \\
nurse & \\
Explanation of what things are like after graduation & $1(0.3 \%)$ \\
Less reflective journaling & $1(0.3 \%)$ \\
More supportive instructors & $1(0.3 \%)$ \\
\hline
\end{tabular}

\section{Discussion}

The purpose of this research is to explore Indigenous nursing students' perceptions of their readiness for practice, and this study adds to the lack of literature in this area. The results are similar to findings from other studies that explored student readiness for practice. Although most senior nursing students agree they are satisfied with their choice of profession, many feel unprepared for at least one aspect of their future role as a registered nurse (Hickey, 2010; Missen, McKenna, \& Beauchamp, 2015; Newton, Cross, White, Ockerby, \& Billet, 2011; Porter, Morphet, Missen, \& Raymond, 2013; Usher, Mills, West, Park, \& Wood, 2015). A common relationship in this study and most comparison studies is an inverse correlation of student confidence and caring for a number of patients: most students are very confident in managing two patients, but few agree they are very confident in managing four patients (Saber et al., 2015; Usher et al., 2015; Woods et al., 2014). However, other studies show little correlation between confidence and caring for a given 
number of patients (Casey et al., 2011). The literature varies regarding interprofessional communication. The present study found students perceive confidence in speaking with physicians and asking for help, in agreement with some previous studies (Casey et al., 2011; Woods et al., 2014) but not others (Saber et al., 2015). Another variable component of readiness for practice is comfort level related to psychomotor skill performance. The current study found students are most uncomfortable performing ECG interpretation and responding to emergency or code situations. This is not uncommon for new graduate nurses (Casey et al., 2011), although a few studies report more student comfort with these skills (Usher et al., 2015; Woods et al., 2014). Different education programs and clinical placements could account for these discrepancies. Participants in the present study felt they had enough opportunity to practice skills more than once, in contrast to participants in other studies (Usher et al., 2015; Woods et al., 2014) who believe they did not have adequate time to practice skills. Variation in location and clinical site placement may account for these differences in perception. Finally, students in the present study report low confidence in their ability to prioritize and delegate, which could be considered part of time management, a common area of reported low confidence for senior nursing students (Hickey, 2010; Newton et al., 2011; Saber et al., 2015).

Several common themes have emerged concerning better preparing students for independent work that are congruent with the experience of participants in the present study. Specifically, these themes include increased education in physiology and pharmacology, increased clinical experience, strong mentorships, and more experience with paperwork and documenting (Casey et al., 2011; Hickey, 2010; Missen et al., 2015; Porter et al., 2013; Saber et al., 2015; Usher et al., 2015). Notably, the learning technique of reflective writing or journaling is found to be the most unhelpful in Usher et al. (2015), Woods et al. (2014), and the present study, but it was the most helpful in Casey et al. (2011).

While the literature reports a range of student perceptions related to their confidence and readiness for practice, the experiences of Indigenous senior nursing students in this study appear to be consistent overall with nursing students in similar studies outlined above. In the literature discussed, the vast majority of participants are Caucasian females in their mid-twenties (Casey et al., 2011; Hickey, 2010; Saber et al., 2015; Usher et al., 2015; Woods et al., 2014). The participants included in this project are solely Indigenous with the majority being female in their late twenties. Both Indigenous and non-Indigenous students share similar perspectives on their readiness for practice; however, we recognize that Indigenous students experience the education and health care system differently than other students due to systemic racism and discrimination they may have encountered (Allan \& Smylie, 2015; Browne, 2017; Reading \& Wien, 2013). This study contributes to the sparse literature on readiness for practice perceptions of Indigenous nursing students and demonstrates that feelings of lack of preparation are common for most senior nursing students as they transition into the workforce.

\section{Implications for Nursing Education}

While our findings are similar to the previous literature on readiness for practice, strategies can be implemented that specifically enhance Indigenous student's readiness for practice. Strategies to facilitate student success and transition support need to be systemic in nature and include and partner with Indigenous and non-Indigenous stakeholders within communities, organizations, and university systems (Smith et al., 2011; West et al., 2013; Wilson et al., 2011). Strategies utilized by nursing education programs should be based on the core nursing education competencies framework outlined by a collaboration between the Canadian Indigenous Nurses 
Association (CINA), the Canadian Association of Schools of Nursing, and the Canadian Nurses Association (Aboriginal Nurses Association of Canada [A.N.A.C.], 2009). The framework highlights the importance of honouring a postcolonial understanding, fostering communication, inclusivity and respect with First Nation, Inuit, and Métis peoples, acknowledging Indigenous knowledge, and encouraging student mentorship and support (A.N.A.C., 2009). As educational institutions and educators, there is a responsibility of non-Indigenous nursing educators to engage in "skills-based training in intercultural competency, conflict resolution, human rights, and antiracism" (TRC, 2015, p. 323). Non-Indigenous educators should enhance their knowledge and awareness of Indigenous culture and history by enrolling in courses and engaging in self-reflection to enhance their understanding of implementing Indigenous student-centred approaches, demonstrate cultural safety, and acknowledge the potential power differential associated with historical relationships between non-Indigenous and Indigenous peoples (Harder et al., 2016; Martin \& Seguire, 2013; Smith et al., 2011; Wilson et al., 2011).

Not all students take advantage of supportive opportunities during their educational program such as tutoring or mentorship supports (Ferrell et al., 2016). More awareness of these support programs and opportunities may be needed. Faculty and student advisors may need to take a more active approach in linking students with available supports. Taking advantage of these types of supportive opportunities may enhance student success and facilitate student perceptions of their readiness for practice. In the open-ended question in this study, students requested mentorship opportunities both within their education programs and to assist with transition into practice. Mentoring relationships are seen as a source of support for Indigenous students and new graduate nurses to facilitate transition into practice and mentorship has been identified as a priority when considering policy direction (A.N.A.C., 2009; Canadian Nurses Association \& Aboriginal Nurses Association of Canada, 2014; Grossman, 2014; Hinton \& Chirgwin, 2010). Mentorship is defined as a mutually beneficial, non-evaluative relationship between a more experienced person (mentor) and a less experienced person (mentee) to aid in personal and professional development (Grossman, 2014; Mills, Francis, \& Bonner, 2005). Matching mentors and mentees who are from similar cultural backgrounds facilitates socialization, role modeling, and support for new graduate nurses (Witkow \& Fuligni, 2011). Mentors who have a similar background as the mentees can understand the cultural realities, opportunities, and challenges of nursing education and readiness for practice (Wilson et al., 2011). Individuals matched with mentors from similar cultural backgrounds report receiving greater support and assistance than others (Blake-Beard, Bayne, Crosby, \& Muller, 2011), and can result in low job turnover and attrition (Banister et al., 2014). Clinical placements caring for Indigenous clients and communities while working alongside Indigenous preceptors can also facilitate postcolonial understanding, increased acknowledgement of Indigenous knowledge, and development of communication, inclusivity, and respect as outlined in the A.N.A.C. (2009) framework. Clinical placements with Indigenous preceptors can provide role modeling and mentorship to Indigenous nursing students (Wilson et al., 2011).

Numerous curriculum strategies have been suggested to better align with and value the ontological perspective of Indigenous nursing students and thus enhance their learning and perhaps their perspective of their readiness. Hands-on opportunities for learning that include additional clinical or laboratory learning experiences are suggested (Parent, 2010; Pijl \& Hagen, 2011; Wilson et al., 2011). These types of practical learning opportunities allow for the facilitation of praxis and connection to concrete experiences and can include psychomotor skill development or simulation scenarios. Visual and observational learning opportunities are also suggested (Parent, 2010; Pijl \& Hagen, 2011). Videos of psychomotor skills, pictures of abstract concepts, and 
utilization of concept maps may be useful strategies to enhance learning and engage all styles of learners. Allowing Indigenous students to observe and watch prior to performing a skill allows for an active learning experience that values Indigenous ways of knowing (Pijl \& Hagen, 2011).

Collaborative group learning opportunities have also been suggested as a strategy to enhance Indigenous student learning (Parent, 2010; Pijl \& Hagen, 2011). Some approaches include problem-based learning scenarios, study groups, or learning circles where clinical situation can be discussed (Cech et al., 2011; Pijl \& Hagen, 2011). These group learning approaches can allow for social support, sharing of experiences, and learning of curriculum material (Wilson et al., 2011), which in turn may help facilitate perceptions of readiness for practice.

\section{Limitations}

A small homogeneous sample size within one province and one university nursing program limits generalizability of the findings and limits the power of the study. The Readiness for Practice Survey has not undergone psychometric analysis with an Indigenous population and no qualitative data were gathered to understand the specificity of this student population. Suggested future research includes a larger scale study exploring Indigenous nursing students' readiness for practice from multiple nursing programs, provinces, and countries to obtain a more global perspective and a larger, heterogeneous sample. Further testing of the Readiness for Practice Survey is needed to determine if the internal consistency of the subscales can be enhanced. Future research will include evaluation of a mentorship program as a means of supporting Indigenous new graduates as they transition to practice. Follow-up evaluations of Indigenous new graduates six months into practice are also planned to assess the supporting and inhibiting factors influencing their transition into the workforce.

\section{Conclusion}

Results from this study demonstrate that Indigenous students share similar perspectives on their readiness for practice when compared with nursing students from the existing literature. Assistance can be put in place to support Indigenous students as they transition into practice. Easing the transition from student to registered nurse requires facilitation and support from Indigenous and non-Indigenous registered nurses, health care team members, academic institutions, communities, and health care organizations (Kumaran \& Carney, 2014). By supporting Indigenous nursing students, preparing them for practice, and providing diverse opportunities to learn, the TRC (2015) Calls to Action pertaining to recruiting and retaining Indigenous nursing professionals can be realized. Strategies to enhance Indigenous nurse readiness for practice can assist in creating a representative workforce and ultimately provide culturally safe quality care for Indigenous individuals and communities. 


\section{References}

Aboriginal Nurses Association of Canada. (2009). Cultural Competence and Cultural Safety in Nursing Education: A Framework for First Nations, Inuit, and Métis Nursing. Ottawa, ON: Author.

Allan, B., \& Smylie, J. (2015). First Peoples, Second Class Treatment: The role of racism in the health and well-being of Indigenous peoples in Canada. Retrieved from http://www.wellesleyinstitute.com/wp-content/uploads/2015/02/Summary-First-Peoples$\underline{\text { Second-Class-Treatment-Final.pdf }}$

Andrews, D. R. (2013). Expectations of millennial nurse graduates transitioning into practice. Nursing Administration Quarterly, 37(2), 152-159. https://doi.org/10.1097/naq.0b013e3182869d9f

Anonson, J., Desjarlais, J., Nixon, J., Whiteman, L., \& Bird, A. (2008). Strategies to support recruitment and retention of First Nations youth in baccalaureate nursing programs in Saskatchewan, Canada. Journal of Transcultural Nursing, 19(3), 274-283. https://doi.org/10.1177/1043659608317095

Banister, G., Bowen-Brady, H. M., \& Winfrey, M. E. (2014). Using career nurse mentors to support minority nursing students and facilitate their transition to practice. Journal of Professional Nursing, 30(4), 317-325. https://doi.org/10.1016/j.profnurs.2013.11.001

Blake-Beard, S., Bayne, M., Crosby, F., \& Muller, C. (2011). Matching by race and gender in mentoring relationships: Keeping our eyes on the prize. Journal of Social Issues, 67(3), 622-643. https://doi.org/10.1111/j.1540-4560.2011.01717.x

Browne, A. J. (2017). Moving beyond description: Closing the health equity gap by redressing racism impacting Indigenous populations. Social Science \& Medicine, 184, 23-26. https://doi.org/10.1016/j.socscimed.2017.04.045

Browne, A. J., Varcoe, C., Lavoie, J., Smye, V., Wong, S. T., Krause, M., ... Fridkin, A. (2016). Enhancing health care equity with Indigenous populations: Evidence-based strategies from an ethnographic study. BMC Health Services Research, 16, 544. https://doi.org/10.1186/s12913-016-1707-9

Boychuk Duchscher, J. (2009). Transition shock: The initial stage of role adaptation for newly graduate registered nurses. Journal of Advanced Nursing, 65(5), 1103-1113. https://doi.org/10.1111/j.1365-2648.2008.04898.x

Canadian Association of Schools of Nursing [CASN]. (2015). National Nursing Education Framework: Final Report. Ottawa, ON: Author.

CASN. (2016). Position Statement: Baccalaureate Education and Baccalaureate Programs. Ottawa, ON: Author.

Canadian Nurses Association \& Aboriginal Nurses Association of Canada. (2014). Aboriginal Health Nursing and Aboriginal Health: Charting Direction for Nursing in Canada. Ottawa, ON: Canadian Nurses Association.

Carr, P. L., Palepu, A., Szalacha, L., Caswell, C., \& Inui, T. (2007). "Flying below the radar": A qualitative study of minority experience and management of discrimination in academic 
medicine. Medical Education, 41, 601-609. https://doi.org/10.1111/j.13652923.2007.02771.x

Casey, K., Fink., R., Jaynes, C., Campbell, L., Cook, P., \& Wilson, V. (2011). Readiness for practice: The senior practicum experience. Journal of Nursing Education, 50(11), 646652. https://doi.org/10.3928/01484834-20110817-03

Cech, E. A., Metz, A. M., Babcock, T., \& Smith, J. L. (2011). Caring for our own: The role of insitutionalized support structures in Native American nursing student success. Journal of Nursing Education, 50(9), 524-531. https://doi.org/10.3928/01484834-20110517-01

Duclos-Miller, P. A. (2011). Successful graduate nurse transition: Meeting the challenge. Nurse Leader, 9(4), 32-49. https://doi.org/10.1016/j.mnl.2011.05.006

Dyess, S. M., \& Sherman, R. O. (2009). The first year of practice: New graduate nurses' transition and learning needs. Journal of Continuing Education in Nursing, 40(9), 403410. https://doi.org/10.3928/00220124-20090824-03

Exner-Pirot, H. (2014). Aboriginal Nursing in Canada. Saskatoon, SK: University of Saskatchewan College of Nursing.

Exner-Pirot, H., \& Butler, L. (2015). Healthy Foundations: Nursing's role in building strong Aboriginal communities. Ottawa, ON: The Conference Board of Canada.

Felton-Busch, C. M., Solomon, S. D., McBain, K. E., \& De La Rue, S. (2009). Barriers to advanced education for Indigenous Australian health workers: An exploratory study. Education for Health, 22(2), 1-7.

Ferrell, D. K., DeCrane, S. K., Edwards, N. E., Foli, K. J., \& Tennant, K. F. (2016). Minority undergraduate nursing student success. Journal of Cultural Diversity, 23(1), 3-11.

Government of Canada. (2017). Indigenous Peoples and Human Rights. Retrieved from https://www.canada.ca/en/canadian-heritage/services/rights-indigenous-peoples.html

Government of Saskatchewan. (2017). Saskatchewan Population Report: 2016 census of Canada. Regina, SK: Statistics Canada.

Gregory, D., \& Barsky, J. (2007). Against The Odds: An update on Aboriginal nursing in Canada. Ottawa, ON: Canadian Association of Schools of Nursing.

Grossman, S. (2014). Mentoring in Nursing: A dynamic and collaborative process (2nd ed.). New York, NY: Springer.

Guner, P. (2014). Preparedness of final year Turkish nursing students for work as a professional nurse. Journal of Clinical Nursing, 24(5-6), 844-854. https://doi.org/10.1111/jocn.12673

Harder, M., Astle, B., Grypma, S., \& Voyageur, E. (2016). Discerning success of Indigenous health students in community-based programs. Quality Advancement in Nursing Education, 2(2), Article 5. https://doi.org/10.17483/2368-6669.1076

Hickey, M. T. (2010). Baccalaureate nursing graduates' perceptions of their clinical instructional experiences and preparation for practice. Journal of Professional Nursing, 26(1), 35-41. https://doi.org/10.1016/j.profnurs.2009.03.001 
Hinton, A., \& Chirgwin, S. (2010). Nursing education: Reducing reality shock for graduate Indigenous nurses - it's all about time. Australian Journal of Advanced Nursing, 28(1), 60-66.

Hoffart, N., Waddell A., \& Young, M. B. (2011). A model of new nurse transition. Journal of Professional Nursing, 27(6), 334-343. https://doi.org/10.1016/j.profnurs.2011.04.011

Jones, C. (2008). Revisiting nurse turnover costs: Adjusting for inflation. Journal of Nursing Administration, 38(1), 11-18. https://doi.org/10.1097/01.nna.0000295636.03216.6f

Katz, J., O’Neal, G., Strickland, C. J., \& Doutrich, D. (2010). Retention of Native American nurses working in their communities. Journal of Transcultural Nursing, 21(4), 393-401. https://doi.org/10.1177/1043659609360848

Kulig, J. C., Lamb, M., Solowoniuk, J., Weaselfat, R., Shade, C, Healy, L., ... Hirsch-Crowshoe, H. (2010). Nurturing a dream: The support program for Aboriginal nursing students. First Nations Perspectives, 3(1), 89-106.

Kumaran, S., \& Carney, M. (2014). Role transition from student nurse to staff nurse: Facilitating the transition period. Nurse Education in Practice, 14, 605-611. https://doi.org/10.1016/j.nepr.2014.06.002

Loftin, C., Newman, S. D., Dumas, B. P., Gilden, G., \& Bond, M. L. (2012). Perceived barriers to success for minority nursing students: An integrative review. International Scholarly Research Network Nursing, 2012, 9 pages, article ID 806543, https://doi.org/10.5402/2012/806543

Martin, D., \& Seguire, M. (2013). Creating a path for Indigenous student success in baccalaureate nursing education. Journal of Nursing Education, 52(4), 205-209. https://doi.org/10.3928/01484834-20130314-01

Metz, A. M., Cech, E. A., Babcock, T., \& Smith, J. L. (2011). Effects of formal and informal support structures on the motivation of Native American students in nursing. Journal of Nursing Education, 50(7), 388-394. https://doi.org/10.3928/01484834-20110415-01

Mills, J., Francis, K., \& Bonner, A. (2005). Mentoring, clinical supervision and preceptoring: Clarifying the conceptual definitions for Australian rural nurses. A review of the literature. Rural \& Remote Health, 5, 410-450.

Minore, B., Boone, M., Cromarty, H., Hill, M., Katt, M., Kinch, P., ... Sabourin, A. (2013). Developing supportive workplace and educational environments for Aboriginal nurses. Thunder Bay, ON: Lakehead University.

Missen, K., McKenna, L., \& Beauchamp, A. (2015). Work readiness of nursing graduates: Current perspectives of graduate nurse program coordinators. Contemporary Nurse, 51(1), 27-38. https://doi.org/10.1080/10376178.2015.1095054

National Aboriginal Health Organization. (2006). Strategic framework to increase the participation of First Nations, Inuit and Métis peoples in health careers. Ottawa, ON: Author.

Newton, J. M., Cross, W. M., White, K., Ockerby, C., \& Billett, S. (2011). Outcomes of a clinical partnership model for undergraduate nursing students. Contemporary Nurse, 39(1), 119-127. https://doi.org/10.5172/conu.2011.39.1.119 
Nunavut Nurses. (2014). Salary and Bonuses. Retrieved from www.nunavutnurses.ca/english/jobs/salary_bonuses.shtml

Nursing Council of New Zealand. (2011). Guidelines for Cultural Safety, The Treaty of Waitangi and Maori Health in Nursing Education and Practice: Regulating Nursing Practice to Protect Public Safety. Wellington, NZ: Author.

O’Brien-Pallas, L., Tomblin-Murphy, G., \& Shamian, J. (2008). Understanding the costs and outcomes of nurses' turnover in Canadian hospitals: Final Report. Toronto, ON: Nursing Health Services Research Unit.

Parent, M. L. (2010). A study on nursing education: A consensus on ideal programs for Aboriginal students. (Doctoral dissertation). Available from ProQuest Dissertations and Theses database. (No. 3398744).

Pijl, E. M., \& Hagen, B. (2011). Towards culturally relevant nursing education for Aboriginal students. Nurse Education Today, 31, 595-600. https://doi.org/10.1016/j.nedt.2010.10.014

Porter, J. (2012, April 20). First Nations hurt by nursing shortage. CBC News. Retrieved from www.cbc.ca/news/canada/thunder-bay/first-nations-hurt-by-nursing-shortage-1.1184843

Porter, J., Morphet, J., Missen, K., \& Raymond, A. (2013). Preparation for high-acuity clinical placement: confidence levels of final-year nursing students. Advances in Medical Education and Practice, 4, 83-89. https://doi.org/10.2147/amep.s42157

Reading, C. L., \& Wien, F. (2013). Health Inequalities and Social Determinants of Aboriginal Peoples' Health. Prince George, BC: National Collaborating Centre for Aboriginal Health.

Saber, D. A., Anglade, D., \& Schirle, L. M. (2015). A study examining senior nursing students' expectations of work and the workforce. Journal of Nursing Management, 24, 183-191. https://doi.org/10.1111/jonm.12322

Smith, D., McAlister, S., Tedford Gold, S., \& Sullivan-Bentz, M. (2011). Aboriginal recruitment and retention in nursing education: A review of the literature. International Journal of Nursing Education Scholarship, 8(1), Article 3. https://doi.org/10.2202/1548-923x.2085

Statistics Canada (2015, September 17) Projections of the Aboriginal population and households in Canada, 2011-2036. Retrieved from http://www.statcan.gc.ca/dailyquotidien/150917/dq150917b-eng.htm

Truth and Reconciliation Commission of Canada [TRC]. (2015). Honoring the truth, reconciling for the future: Summary of the final report of the truth and reconciliation commission of Canada. Winnipeg, MB: Author.

Usher, K., Mills, J., West, C., Park, T., \& Woods, C. (2015). Preregistration student nurses' selfreported preparedness for practice before and after the introduction of a capstone subject. Journal of Clinical Nursing, 24, 3245-3254. https://doi.org/10.1111/jocn.12996

Vakic, A., Jesty, C., Mathews, V., \& Etowa, J. (2012). Understanding race and racism in nursing: Insights from Aboriginal nurses. International Scholarly Research Network, 2012, Article ID 196437, 1-9. https://doi.org/10.5402/2012/196437 
West, R., Usher, K., Buettner, P. G., Forster, K., \& Stewart, L. (2013). Indigenous Australians' participation in pre-registration tertiary nursing courses: A mixed methods study. Contemporary Nurse, 46(1), 123-134. https://doi.org/10.5172/conu.2013.46.1.123

Wilson, D., McKinney, C., \& Rapata-Hanning, M. (2011). Retention of Indigenous nursing students in New Zealand: A cross-sectional survey. Contemporary Nurse, 38(1-2), 5975. https://doi.org/10.5172/conu.2011.38.1-2.59

Witkow, M. R., \& Fuligni, A. J. (2011). Ethnic and generational differences in the relations between social support and academic achievement across the high school years. Journal of Social Issues, 67(3), 531-552. https://doi.org/10.1111/j.1540-4560.2011.01713.x

Woods, C., West, C., Mills, J., Park, T., Southern, J., \& Usher, K. (2014). Undergraduate student nurses' self-reported preparedness for practice. Collegian, 22, 359-368. https://doi.org/10.1016/j.colegn.2014.05.003 